\title{
Triggering and propagation of exogenous sediment pulses in mountain channels: insights from flume experiments with seismic monitoring
}

\author{
Marco Piantini ${ }^{1,2}$, Florent Gimbert ${ }^{1}$, Hervé Bellot $^{2}$, and Alain Recking ${ }^{2}$ \\ ${ }^{1}$ University Grenoble Alpes, CNRS, IRD, Institute for Geosciences and Environmental Research (IGE), \\ Grenoble, France \\ ${ }^{2}$ University Grenoble Alpes, INRAE, ETNA, Grenoble, France
}

Correspondence: Marco Piantini (marco.piantini@univ-grenoble-alpes.fr)

Received: 25 March 2021 - Discussion started: 26 April 2021

Revised: 5 August 2021 - Accepted: 28 September 2021 - Published: 4 November 2021

\begin{abstract}
In the upper part of mountain river catchments, large amounts of loose debris produced by masswasting processes can accumulate at the base of slopes and cliffs. Sudden destabilizations of these deposits are thought to trigger energetic sediment pulses that may travel in downstream rivers with little exchange with the local bed. The dynamics of these exogenous sediment pulses remain poorly known because direct field observations are lacking, and the processes that control their formation and propagation have rarely been explored. Here we carry out flume experiments with the aims of investigating (i) the role of sediment accumulation zones in the generation of sediment pulses, (ii) their propagation dynamics in low-order mountain channels, and (iii) the capability of seismic methods to unravel their physical properties. We use an original setup wherein we supply liquid and solid discharge to a low-slope storage zone acting like a natural sediment accumulation zone that is connected to a downstream $18 \%$ steep channel equipped with geophones. We show that the ability of the selfformed deposit to generate sediment pulses is controlled by the fine fraction of the mixture. In particular, when coarse grains coexist with a high content of finer particles, the storage area experiences alternating phases of aggradation and erosion strongly impacted by grain sorting. The upstream processes also influence the composition of the sediment pulses, which are formed by a front made of the coarsest fraction of the sediment mixture, a body composed of a high concentration of sand corresponding to the peak of solid discharge, and a diluted tail that exhibits a wide grain size distribution. Seismic measurements reveal that the front dominates the overall seismic noise, but we observe a complex dependency between seismic power and sediment pulse transport characteristics, which questions the applicability of existing seismic theories in such a context. These findings challenge the classical approach for which the sediment budget of mountain catchments is merely reduced to an available volume, since not only hydrological but also granular conditions should be considered to predict the occurrence and propagation of such sediment pulses.
\end{abstract}

1

Sediment transport processes play a key role in fluvial geomorphology (Schumm, 2003) and natural risk management (Badoux et al., 2014), since they exert a major control on the intensity with which rivers can impact the landscape and the safety of inhabited regions. This is particularly evident in mountain catchments, where catastrophic floods are ex- acerbated by a rapid hydrological response to rainfall (high hydrological connectivity; Wohl, 2010) and a large mobilization of sediments (Recking, 2014). Predicting when and how sediments move throughout mountain channels, however, remains challenging since onset of motion criteria and bedload transport laws have mostly been established for lowland rivers and have limited applicability to mountain environments (Schneider et al., 2016). Mountain rivers are charac- 
terized by a wide range of morphological units whose peculiarities cannot be neglected when studying sediment transport (Lee and Ferguson, 2002; Comiti et al., 2009; Zimmermann et al., 2010). For instance, several works have shown that large-scale bed roughness is expected to affect bed shear stress (Bathurst et al., 1983; Wiberg and Smith, 1991; Solari and Parker, 2000; Lamb et al., 2008; Recking, 2009; Prancevic and Lamb, 2015), and grain sorting processes have a stronger impact in term of producing bedload fluctuations compared to lowland streams (Recking et al., 2009; Bacchi et al., 2014). Moreover, the steepness of mountain channels may help trigger debris flows, which are energetic transport processes whereby the solid volume fraction is so high (greater than $50 \%$ ) that the solid phase influences the behaviour of the flow as much as the fluid phase (Iverson, 1997). The conditions of transition from bedload to debris flow remain debated, partly due to lacking field observations (Mao et al., 2009; Prancevic et al., 2014).

For both fluvial and debris flows processes, in addition to the hydrological forcing, sediment supply conditions play an important role (Benda and Dunne, 1997; Bovis and Jakob, 1999; Recking, 2012) and their spatial and temporal variabilities add complexity to predictions. Mountain channels that are coupled to sediment production zones (high landscape connectivity; Wohl, 2010) are particularly prone to receiving episodic inputs of material coming from upstream sections of the catchment, where sediments produced by mass-wasting processes accumulate in the form of talus slope or along lowslope stretches as loose scree deposits. However, this storage is often temporary, since rainfall and runoff descending from upper slopes can destabilize these accumulation zones and trigger sediment transport towards downstream channels (Berti et al., 1999; Fontana and Marchi, 2003; Gregoretti and Fontana, 2008). This is, for example, the case in the Roize River, France (Fig. 1a). The upper part of the catchment is characterized by cliffs producing a large amount of debris that accumulates at the slope's toe (Fig. 1b and Lamand et al., 2017), and as a result of hydrological and gravitational phenomena, sediments are occasionally released to the coupled reach (Fig. 1c) where they are transported downstream to a reception zone (sediment trap). The dynamics of transport throughout the river reach have been shown to be strongly related to the activity of these headwater sediment sources (Piton and Recking, 2017). Thanks to exogenous inputs of sediments, such streams can suddenly switch from supplylimited to overcapacity conditions, as illustrated in Fig. 2 showing that the non-alluvial and inactive bed of the Ruisseau de la Gorge (French Alps) suddenly experienced a large transport event in 2015. As the transported sediments were much finer than the bed in place, an upstream and exogenous input of the material was suggested.

Several works have shown that exogenous sediment inputs in a river usually take the form of sediment pulses, defined in the literature as disturbances in bed elevation that propagate downstream, translating as a coherent wave and/or dispers-
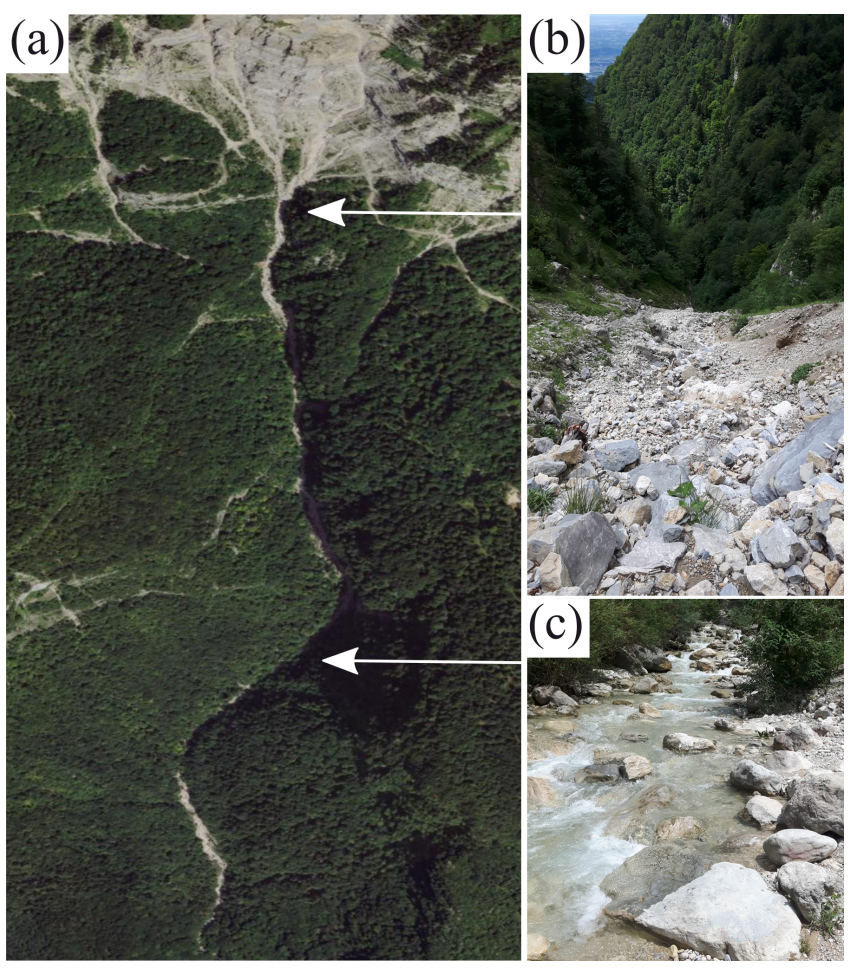

Figure 1. (a) The Roize River, a typical mountain stream configuration with (b) a production zone with sediment deposits that are several metres thick and show evidence of large incisions and (c) a transfer zone consisting of a narrow steep step-pool morphology. Photo credit: (a) IGN France (https://www.geoportail.gouv.fr, last access: 16 July 2020).

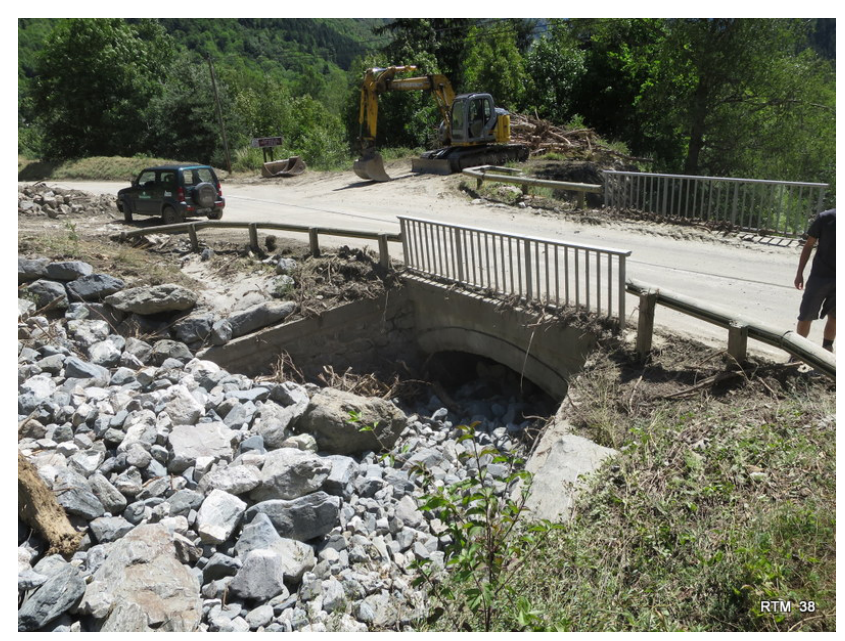

Figure 2. Effect of a sediment pulse at a bridge section of the Ruisseau de la Gorge (France), a stream that was known by local engineers as having been inactive for decades. The transported material was much finer $\left(D_{50}=96 \mathrm{~mm}, D_{84}=169 \mathrm{~mm}\right)$ than the bed in place $\left(D_{50}=250 \mathrm{~mm}, D_{84}=413 \mathrm{~mm}\right)$. 
ing in place (Sutherland et al., 2002; Brummer and Montgomery, 2006). Previous studies have investigated the evolution of these sediment pulses in gravel-bed rivers characterized by a maximum slope of $1 \%$, wherein the streambed has been shown to actively interact with the injected material (Lisle et al., 1997; Sutherland et al., 2002; Cui et al., 2003; Cui and Parker, 2005; Sklar et al., 2009). However, low-order mountain rivers usually present geological controls such as rarely mobile boulders and bedrock outcrops, as well as much steeper slopes. In this context, sediment pulses are expected to be transported downstream with a marginal morphological impact on the underlying bed, following the "travelling bedload" concept (Piton and Recking, 2017). To the best of our knowledge, there are no experimental studies that investigate sediment pulse propagation in such a configuration, and the few post-event field observations do not provide information about their spatial and temporal dynamics. Classical monitoring methods reveal scarce effectiveness for observing pulse-like events (Mao et al., 2009), and therefore sediment pulses are challenging to track due to their localized and potentially energetic nature. In this context, seismic methods represent a robust alternative for providing a non-invasive and continuous monitoring of torrential processes (Burtin et al., 2016) and catastrophic floods (Cook et al., 2018). As sediment transport generates ground vibrations, mechanistic models have been defined to understand the links between river processes and the generated seismic noise (Tsai et al., 2012; Gimbert et al., 2014; Lai et al., 2018; Farin et al., 2019). Applicability of seismic theories for bedload under a relatively low transport rate has been demonstrated in the laboratory (Gimbert et al., 2019) and in the field (Bakker et al., 2020). Seismic models for more concentrated sediment flows have also been tested in the laboratory in the context of dry granular flows (Arran et al., 2021) and in the field in the context of debris flows (Zhang et al., 2021). However, the extent to which existing theories apply to a variety of sediment transport flows including sediment pulses, which may lie between bedload transport and debris flows, remains to be investigated.

In this study we conduct laboratory experiments (i) to explore the role of sediment accumulation zones in the generation of sediment pulses, (ii) to investigate their propagation dynamics in low-order mountain channels, and (iii) to test the capability of seismic methods to infer the flow properties associated with such sediment transport events. We use an original setup wherein instead of feeding the flume section directly as usually done, we supply liquid and solid discharge to a low-slope storage zone connected to the upstream part of a $18 \%$ steep channel. Such an experimental configuration allows us to investigate if a self-formed deposit can generate sediment pulses and how these later propagate in the downstream channel. In Sect. 2 we present the experimental setup and the measurement protocol. Then in Sect. 3 we present our experimental results regarding both the storage area and the channel. Finally, in Sect. 4 we discuss the key results and describe the main implications for mountain stream morphodynamics.

\section{Material and methods}

\subsection{Experimental setup and measurements}

We use a $6 \mathrm{~m}$ long flume made of (i) a $1 \mathrm{~m}$ long and on average $0.5 \mathrm{~m}$ wide trapezoidal-shaped upstream storage area ( $\sim \%-1 \%$ ) and (ii) a $5 \mathrm{~m}$ long and $0.1 \mathrm{~m}$ wide downstream steep (18\% slope) channel (Fig. 3).

Water discharge recirculation is ensured by a pump supplied by a reservoir placed at the flume outlet, whose level is kept constant through an overflow drain. The discharge value is measured with an electromagnetic flowmeter, and the flow rate is controlled numerically using a calibrated voltagedischarge relationship. We use a sediment feeding system composed of a hopper connected to a conveyor belt for the solid discharge. The sediment flux is controlled by the velocity of the conveyor belt, which is measured by a sensor fixed on one of its rotation axes. As for the water supply we set a calibrated equation in order to regulate the solid discharge from the computer.

The topographic evolution of the storage area is monitored with a sensing camera (Microsoft Kinect) that allows us to reproduce a virtual 3-D model from the images through depthsensing techniques: a light is firstly projected by an infrared sensor; then the reflected pattern is captured to recover the geometry of the object by computing the light's time of flight. The device is used to estimate the volume variation of the deposit and its longitudinal slope.

We video record each experiment with two webcams placed at the inlet section and along the channel (Microsoft HD LifeCam Cinema). Three sections are equipped with a remote transducer ultrasonic sensor (Banner Q45UR Series) having a sampling frequency of $100 \mathrm{~Hz}$ and a geophone (3-D Geophone PE-6/B) (Fig. 3) to respectively measure the flow surface elevation and detect flow-induced seismic flume motion generated by particle impacts (Govi et al., 1993). The data from the geophones are recorded on a DATA-CUBE ${ }^{3}$ logger with a sampling frequency of $800 \mathrm{~Hz}$. In order to explore the properties of the seismic noise, we compute the power spectral density (PSD) of the signal recorded along the vertical by performing a fast Fourier transform with the Welch's averaging method (Welch, 1967). According to this method the time series is split into overlapping segments (here we chose an overlap of $50 \%$ ), and the final PSD results from the average of the PSDs of each segment. We focus on sediment-transport-related seismic noise by getting rid of other sources emitted by the experimental device (e.g. water pump, water flow in pipes and on the flume) through normalizing the raw signal by the seismic power occurring under similar experimental conditions but with no sediment transport (see Sect. S2 in the Supplement). We measure the sediment flux by sampling the outgoing sediments at the channel 


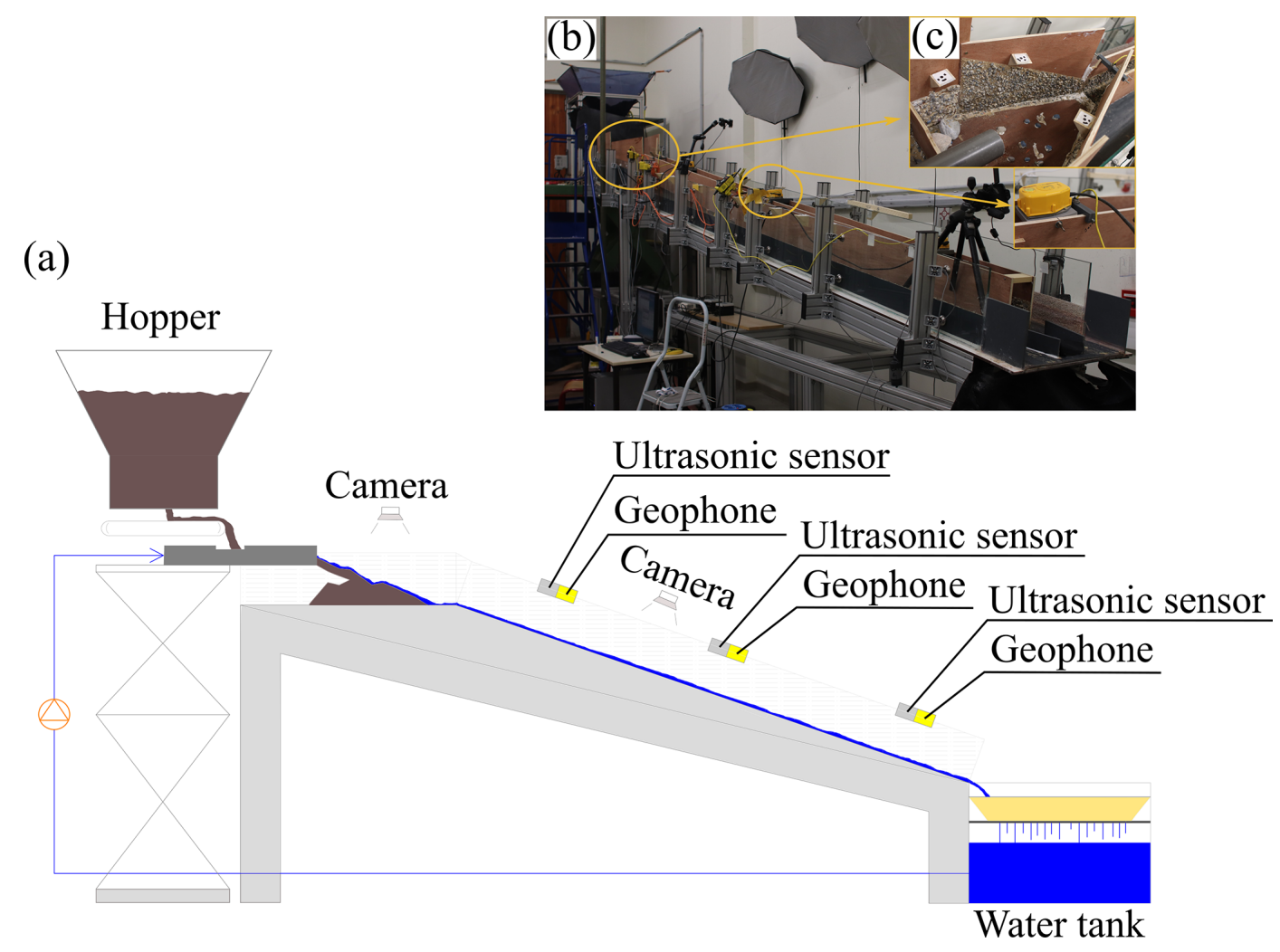

Figure 3. (a) Scheme of the flume with the instrumental equipment. (b) A photo of the flume. (c) A zoom-in of (i) the upstream storage area and (ii) one of the three sections equipped with a geophone (yellow device) and an ultrasonic sensor (grey housing).

exit, and we compute the grain size distribution of the samples from sieve measurements. It is worth noting that solid discharge is measured by hand and is consequently not continuous in time, and the sampling frequency is adapted to flow conditions. As flow surface elevation and seismic noise are monitored at a different section than the outlet solid discharge, a time lag between measurements is present. In order to compute the expected temporal delay and to properly compare the measured data, we time-shift the outlet solid discharge by estimating the velocity of the flux with a cross-correlation between the three flow surface elevation time series. Such a time-shift procedure is appropriate for the seismic analysis thanks to significant signal amplification $(+5 \mathrm{~dB}$ on average) occurring near the geophone in our experimental setting (see Sect. 4 in the Supplement).

\subsection{Experimental scaling and input conditions}

Although this work does not aim at being the analogue of a particular natural prototype, we have built the flume and set the boundary conditions under several scaling considerations. While the dimensionless characteristics of the flume (e.g. slope and sediment transport concentration) can be directly compared to the field, the definition of a scaling parameter is required to estimate the scale reduction of other dimensional parameters of the flume. We follow the approach of Piton (2016) and define a geometrical scaling parameter $\lambda$ as the ratio between a characteristic particle diameter of the natural and experimental river. We choose the 84th percentile grain diameter as a proxy for bed roughness, which exerts a major control on river hydraulics:

$\lambda=\frac{D_{84, \text { natural channel }}}{D_{84, \text { experimental channel }}}$,

where $D_{84}$, natural channel is the characteristic particle diameter of the natural channel and $D_{84}$, experimental channel is that of our experimental setup.

Mountain channels are typically characterized by a wide bimodal grain size distribution ranging from fine elements to large boulders provided by an external sediment supply (Wolcott, 1988; Casagli et al., 2003; Sklar et al., 2017). This is why we choose a bimodal grain size distribution characterized by two modes corresponding to sand $(0.5 \mathrm{~mm}<D<$ $2 \mathrm{~mm}$ ) and cobbles $(4 \mathrm{~mm}<D<8 \mathrm{~mm})$ (Table 1 and Fig. 4 ) as input. The poorly sorted mixture is obtained with respect to grain size distribution utilized in previous experimental works on steep slopes (Bacchi et al., 2014) and is characterized by $D_{50}=5.16 \mathrm{~mm}$ and $D_{84}=9 \mathrm{~mm}$. In order to reproduce the immobile natural roughness of confined bedrock torrents, we glue sediments to the bed and side walls of the flume. 


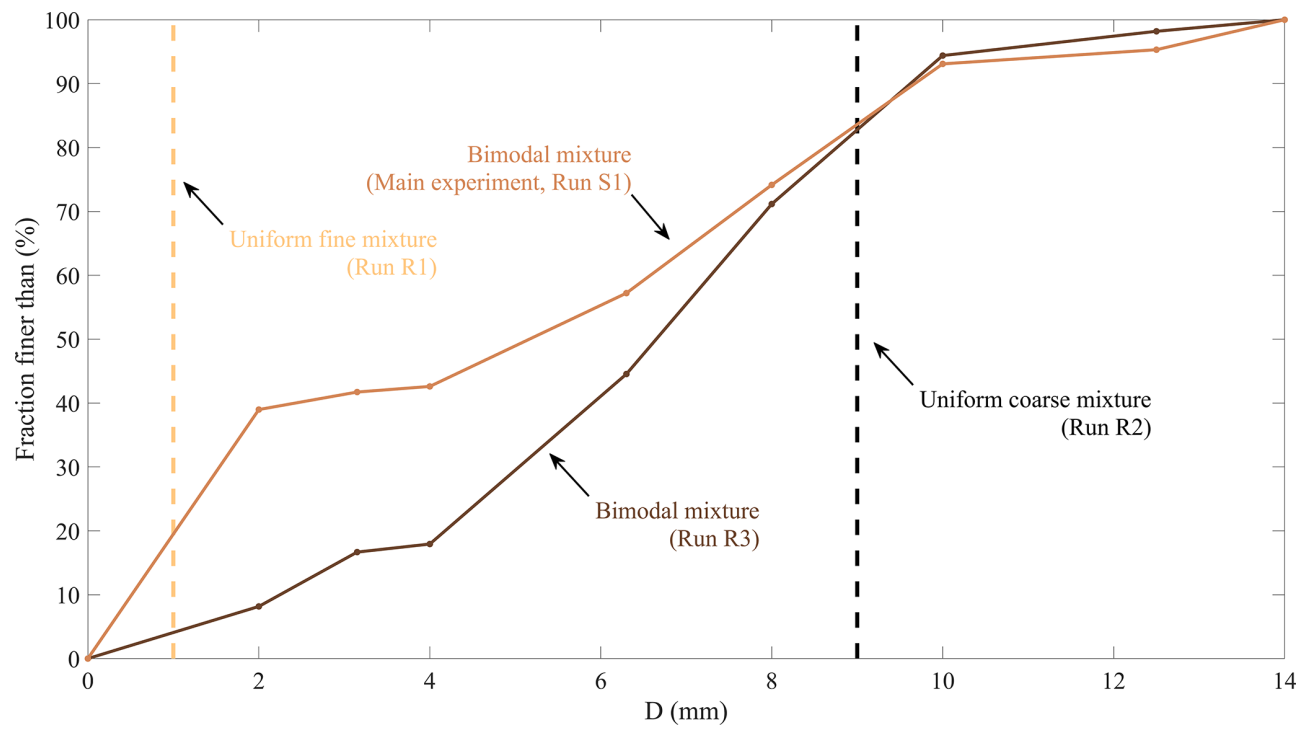

Figure 4. Grain size distribution of the different sediment mixtures used in the experiments.

Table 1. Experimental conditions.

\begin{tabular}{lll}
\hline Main experiment & Reference experiments & Supplementary experiment \\
\hline$Q_{l}=0.451 \mathrm{~s}^{-1}$ & Varying grain size distribution: & Without storage area: \\
$Q_{s}=80 \mathrm{~g} \mathrm{~s}^{-1}$ & (1) Run R1: uniform fine mixture & (4) Run S1 \\
$C=6.7 \%$ & (2) Run R2: uniform coarse mixture & \\
$F r=1.66$ & (3) Run R3: bimodal mixture with a reduced fine fraction & \\
$R e=2417$ & & \\
$R e^{*}=530$ & & \\
$H / D 84=0.70$ & \\
$\tau^{*}=0.08$ & & \\
$\tau_{\mathrm{cr}}^{*}=0.09$ & & \\
$\tau^{*} / \tau_{\mathrm{cr}}^{*}=0.89$ & & \\
Duration $=0.5 \mathrm{~h}$ & \\
Bimodal mixture & & \\
\hline
\end{tabular}

Considering two well-documented steep mountain streams as reference natural channels, the Rio Cordon River (Italy) (Lenzi et al., 2004; Mao and Lenzi, 2007; Schneider et al., 2014) and the Erlenbach River (Switzerland) (Turowski et al., 2009; Schneider et al., 2014), we obtain $\lambda \approx 32$ computed as the average of those two reference streams $(\lambda=41$ for the Rio Cordon and $\lambda=23$ for the Erlenbach).

Following the guidelines of Peakall et al. (1996), channel width and length as well as depositional height are expected to scale linearly with $\lambda$, while the liquid discharge per unit channel is expected to scale as $\lambda^{1.5}$. Our experimental flume width is thus equivalent to a natural channel width of about $3.2 \mathrm{~m}$, consistent with typical mountain stream widths (see Table 2). The upscaled channel length corresponds to $160 \mathrm{~m}$, which can be considered a natural channel reach. The dimensionless experimental slope of $18 \%$ falls within the range of steep mountain streams (see Table 2).
Table 2. Main characteristics of the Rio Cordon and Erlenbach rivers considered to scale the experimental conditions. The values of liquid discharge for the reference channels refer to a recurrence interval of 5 years (Schneider et al., 2014). The upscaled experimental values are computed using $\lambda=32$.

\begin{tabular}{lrrr}
\hline & Rio Cordon & Erlenbach & Upscaled experiments \\
\hline$D_{84}(\mathrm{~mm})$ & 366 & 206 & 288 \\
Slope $(\%)$ & 13.6 & 15 & 18 \\
Width $(\mathrm{m})$ & 5.3 & 3.5 & 3.2 \\
$Q_{l}\left(\mathrm{~m}^{2} \mathrm{~s}^{-1}\right)$ & $\approx 1.14$ & $\approx 0.87$ & $\approx 0.80$ \\
\hline
\end{tabular}

Concerning the upstream storage area, its size is mainly dictated by technical constraints since we use a preexisting steel channel as support for the flume (Fig. 3). Nevertheless, the chosen geometry leads to the formation of a maximum $\approx 0.15 \mathrm{~m}$ thick deposit, which would correspond to a deposit 
about $5 \mathrm{~m}$ thick in a natural context, consistent with field observations in mountain upper catchments (Berti et al., 1999; Imaizumi et al., 2006). The basal slope in the storage area is arbitrarily set to $\sim 0-1 \%$ in order to reduce the transport capacity and let the deposit develop. The influence of the storage area geometry on the observed processes is discussed in Sect. 4.1.

We chose the flow discharge with respect to standard similitude criteria. In particular, we verify that the channel's flow conditions are supercritical ( $\mathrm{Fr}>1)$, fully turbulent ( $\operatorname{Re}>2000)$, and hydraulically rough $\left(\mathrm{Re}^{*}>70\right)$ by computing the Froude (Fr), Reynolds ( $\mathrm{Re}$ ), and Reynolds particle number $\left(\mathrm{Re}^{*}\right)$ consistently with natural mountain streams (Peakall et al., 1996; Asano and Uchida, 2016). Estimating these parameters requires an estimate of the flow velocity, which is computed following Rickenmann and Recking (2011). Finally, considering the above requirements and the flume setup, we prescribe liquid discharge per unit channel width of $0.0045 \mathrm{~m}^{2} \mathrm{~s}^{-1}$, which is equivalent to about $0.80 \mathrm{~m}^{2} \mathrm{~s}^{-1}$ in the field. From Schneider et al. (2014), this discharge value is associated with flood events having a recurrence interval of about 5 years for the Rio Cordon and the Erlenbach rivers. The feeding of the upstream storage area is set in order to obtain a high solid concentration $(C=6.7 \%$, computed here as $Q_{s} / Q_{l}$ ).

The main experiment is characterized by an in-channel transport stage $\tau^{*} / \tau_{\mathrm{cr}}^{*}$ close to 1 , where $\tau^{*}$ is the mean Shields stress and $\tau_{\mathrm{cr}}^{*}$ the critical Shields stress. We calculate the mean Shields stress as $\tau^{*}=\frac{\tau}{g\left(\rho_{\mathrm{s}}-\rho\right) D_{84}}$, where bed shear stress is approximated under the assumption of uniform flow as $\tau=\rho u_{*}^{2}, \rho$ is water density, and $u_{*}=\sqrt{g h S}$ is the bed shear stress velocity, with $h$ equal to water level, $S$ being the channel slope, $g$ acceleration due to gravity, $\rho_{\mathrm{s}}$ sediment density, and $D_{84}$ the 84 th percentile particle diameter. The critical shear stress is considered slope-dependent and formulated following Recking et al. (2008) as $\tau_{\mathrm{cr}}^{*}=0.15 \mathrm{~S}^{0,275}$.

The overall experimental conditions are summarized in Table 1 .

\subsection{Additional experiments}

In addition to the main experiment, we conduct additional experiments with different grain size distributions in order to explore the effect of grain size heterogeneity on the behaviour of the deposit. We test a bimodal distribution characterized by a reduced amount of sand (30\% less in weight, Run R3 in Table 1 and Fig. 4) and two nearly uniform mixtures characterized by a mean diameters of $1 \mathrm{~mm}$ and $9 \mathrm{~mm}$ : Run R1 and Run R2, respectively, in Table 1 and Fig. 4. We also carry out a supplementary experiment (Run S1 in the Supplement) that consists of feeding the $18 \%$ steep channel directly using the bimodal mixture of the main experiment. Input liquid and solid discharge values are kept constant for each run.

\section{Results}

\subsection{Dynamics of the deposit in the storage area}

The temporal variation of the deposit's volume detected using the Kinect camera measurements during the main experiment is shown with the brown curve in Fig. 5a, while the mechanisms involved in its evolution are investigated by looking at an associated video (Piantini et al., 2021a) and selected images (Fig. 5). During the first minutes (about $5 \mathrm{~min}$ ), the flow is characterized by a limited transport capacity, which results in nearly total deposition with no sediments reaching the downstream channel. The water flow mainly bypasses the deposit on the sides, although some infiltration also occurs, as attested by subsurface flows coming out of the deposit toe. However, after about 6 min a large portion of the deposit is submerged, while its upper part experiences a thin but significant surface water flow (Piantini et al., 2021a). Local failures efficiently move clusters of sediments at the front of the deposit and on the flanks such that the deposit grows in the vertical and horizontal direction until it approaches the connected steep channel. We observe that grains at the surface are preferentially coarse as a result of the downward percolation of finer particles (kinematic sieving; sensu Frey and Church, 2009). These bigger grains create an armour at the surface and also roll to the deposit's toe (yellowbordered particles in Fig. 5c), with both processes stabilizing the whole mass. At this stage, the volume reaches its maximum (point 1 in Fig. 5a) with a slope of $\approx 53 \%$ (brown curve in Fig. 5b) when the armour suddenly breaks and a major en masse failure of the deposit is triggered. The armour breaking leads to the formation of a channelized flow that erodes the deposit and transports sediments over a smooth bed of sand previously hidden in the subsurface (point 2 in Fig. 5a and red-bordered area in Fig. 5d). After this first large destabilization that evacuates the eroded material towards the downstream main channel, the deposit reaches its lowest longitudinal slope $(\approx 25 \%)$ that results in a decreased transport capacity. However, some sediments are still prone to leave the storage area through a small incised channel such that the total volume does not change significantly (plateau that lasts nearly $300 \mathrm{~s}$ after point 2 in Fig. 5a). A new armoured surface starts developing with the formation of bars made of coarse particles, which makes a new aggradation phase possible as the water flow becomes shallow and unchannelized (the sheet flow described by Parker, 1998). The deposit reaches another peak in volume with a heavily armoured surface (point 3 in Fig. 5 a and e) before another destabilization occurs. We observe four alternating aggradation and erosion phases until the end of the run, interspersed with minor releases to the channel (see black arrows in Fig. 5a). Aggradation and erosion phases fluctuate between an average deposit slope of $\approx 48 \%$ (range $45 \%-53 \%$ ) and $23 \%$ (range $22 \%-25 \%$ ), respectively. The last $1000 \mathrm{~s}$ of the experiment are characterized by a generalized depletion of material due 
to the congestion of the storage area that is no longer able to retain sediments.

Interestingly, we find that the alternating behaviour as described above no longer occurs when using uniform sediment mixtures. The experiment using the mixture of sand (Run R1) first exhibits an aggradation phase during the first $250 \mathrm{~s}$ (cream-coloured curve in Fig. 5a), but sand quickly reaches the inlet section of the channel and the storage area starts to release sediments with a mean solid discharge of $156 \mathrm{~g} \mathrm{~s}^{-1}$ before reaching an equilibrium with the inlet solid discharge (Piantini et al., 2021b). The plateau in the creamcoloured curve of Fig. 5 indicates that an equilibrium phase is achieved with no significant deposition or erosion. The experiment carried out with the coarse mixture (Run R2) leads to the formation of a steep pile in front of the injection tube. As the mobility of the grains is low, the deposit grows quickly in the vertical direction and reaches the height of the injection tube long before approaching the channel inlet. Other than the interlocking effect of the particles, the video recording (Piantini et al., 2021c) clearly shows that the high permeability of the mixture causes the water to fully infiltrate, leading to nearly dry flow conditions at the surface (no water surface flow). We observe a similar behaviour in Run R3 using a bimodal mixture characterized by a low percentage of sand (around $10 \%$ by weight, Fig. 4), a video recording of which is presented by Piantini et al. (2021d) and for which the deposit shows strong stability with no pulses generated. The different mobility of the three mixtures presented here is materialized by the longitudinal profile computed for each experiment during the maximum extension of the deposit (Fig. 5b). Sand easily reaches the inlet section of the channel, and particles are washed away by the flow by preventing the deposit from growing in volume (cream-coloured curve in Fig. 5b). The coarse material is on the other side of the spectrum as the stability of the mixture allows the deposit to reach a $66 \%$ longitudinal gradient (burgundy curve in Fig. 5b). Between these two conditions, the deposit made of the bimodal mixture is able to develop radially thanks to local destabilizations that spread material towards the channel (brown curve in Fig. 5b).

Based on these observations, we hypothesize that, in our experiments, the ability of the deposit to experience alternating phases of storage and erosion with the generation of sediment pulses is controlled by the presence of sand and its downward percolation through the coarser grains. The processes potentially involved are discussed in Sect. 4.2.

\subsection{Sediment pulse propagation in the downstream channel}

We investigate the propagation and physical characteristics of sediment pulses with a specific experiment focused on the channel having the boundary conditions of the main experiment (see Table 1). We use the middle section's ultrasonic and geophone sensors, as well as manual measurements of sediment flux and grain size distribution at the channel outlet. After the time-shifting procedure (see Sect. 2.1), we find a clear correlation between flow surface elevation and solid discharge measurements (Fig. 6): the passage of sediment pulses causes distinct peaks of about $60 \mathrm{~s}$ in the flow surface elevation time series (Fig. 6a). The biggest peaks are associated with a solid discharge of about $340 \mathrm{~g} \mathrm{~s}^{-1}$ (Fig. 6b), which is up to 4 times larger than the prescribed solid input of $80 \mathrm{~g} \mathrm{~s}^{-1}$, and a sediment concentration that reaches $26.8 \%$ in volume. The magnitude of the sediment pulses is controlled by the dynamics of the upstream storage area, as confirmed by the supplementary experiment Run S1 in the Supplement in which we feed the $18 \%$ steep channel directly with the same bimodal sediment mixture and observe no significant solid discharge fluctuations (Piantini et al., 2021e). The second solid discharge peak around $t=700 \mathrm{~s}$ is smaller than the others, since its height is $\sim 1 \mathrm{~cm}$ and its mean solid discharge is almost equal to the prescribed solid input $\left(Q_{\mathrm{S}}=84 \mathrm{~g} \mathrm{~s}^{-1}\right)$. We find that this pulse is the result of a sediment release occurring just before the second cycle of aggradation-erosion in the upstream storage area (see Sect. 3.1).

The three sediment pulses that result from major destabilizations in the storage area are all characterized by the same composition (Fig. 7a): a front made of the coarsest fraction of the sediment mixture, a body that exhibits a predominance of sand, and a tail characterized by a wide grain size distribution (Fig. 7b). This varying grain size distribution mainly results from the processes that occur in the storage area. The front made of the coarsest particles constituting the deposit surface $\left(D_{84}=12.12 \mathrm{~mm}\right.$ on average from all front samples) is inherited from the coarser grains being the first ones to be destabilized in the storage area. These coarser grains always precede the peak of solid discharge and are materialized in the flow surface elevation measurements by a small bump preceding the main pulse's peaks (Fig. 6a). In contrast, the sand, which is initially hidden below the surface in the storage area, only emerges and is transported towards the channel when the bulk mass is destabilized. This large destabilization constitutes the peak in flow surface elevation, which exhibits finer grains $\left(D_{84}=7.43 \mathrm{~mm}\right)$ and the highest concentration of sand ( $33 \%$ by weight). The falling limb of the sediment pulse is composed of a wider grain size distribution $\left(D_{84}=7.85 \mathrm{~mm}\right)$ with a high percentage of sand as well (40\% by weight), but with decreased solid discharge as a result of the next aggradation phase starting to store sediments in the storage area. This peculiar composition is absent in the second solid discharge peak, at which all the samples exhibit an average $D_{84}=8.63 \mathrm{~mm}$ with little inter-sample variation.

The video recorded $1 \mathrm{~m}$ upstream of the middle section (Piantini et al., 2021f) allows us to characterize the transport mechanics associated with each part of the pulse. The pulse's front exhibits typical bedload dynamics with grains saltating, rolling, and sliding on the bed (see the first $15 \mathrm{~s}$ in Piantini et al., 2021f). The coarsest fraction occasionally gets stuck and forms small lateral clusters, consistent with transport for 


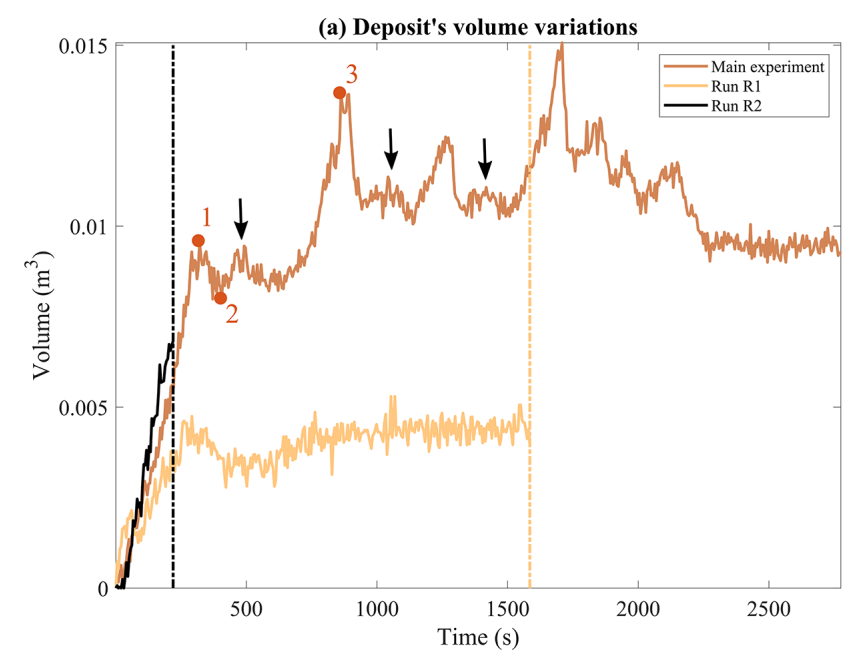

(d)

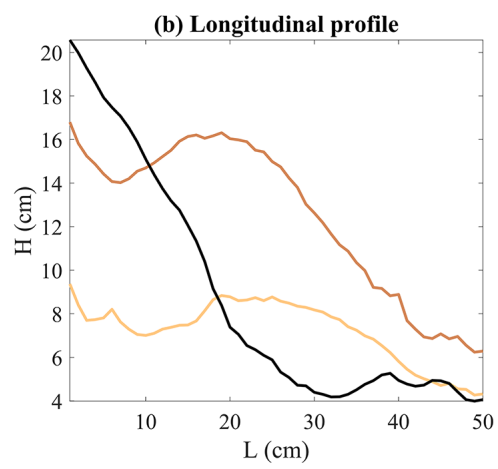

(e)

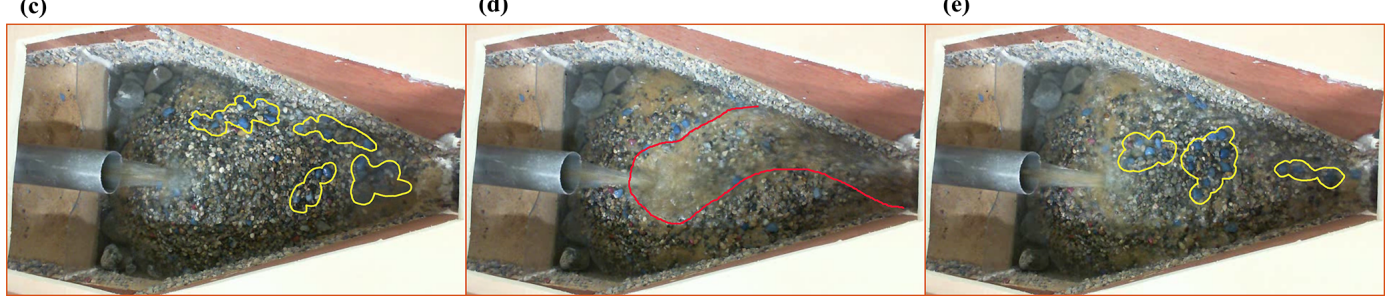

Figure 5. (a) Results from the Kinect camera for the three runs. The volume variation of the deposit is shown versus time. The two vertical dotted lines show the end of the runs with the uniform mixtures. The black arrows indicate the sediment releases occurring after the larger destabilizations and before the following aggradation phase described in the text. The orange dots and numbers refer to the images below. The frames of the video recording represent the steps of the cyclic behaviour experienced by the storage area, with the following: (c) the aggradation phase of the deposit and armouring at its maximum; (d) the sediment pulse to the channel following the destabilization of the deposit with sand no longer hidden but exposed to the flow; (e) a new armouring phase. The yellow-bordered particles form the surface armour, while the red-bordered area shows the destabilized mass. (b) Comparison between the longitudinal profiles of the deposit for the three experiments when the aggradation phase is at its maximum. The profile is the result of the intersection between the deposit and a plane normal to the storage area's base and parallel to the channel.

these large grain sizes occurring near the threshold of motion (see Sect. 2.2). These bedforms are ephemeral since sudden impacts of grains can destroy their structure, incorporating them into the main flow and causing the motion of the biggest elements constituting the front to be quite intermittent. The pulse's body is conversely characterized by enhanced mobility. Our instrumental equipment does not allow us to deeply investigate the nature of the interactions occurring in this dense granular flow (i.e. collisional or frictional; sensu GDR MiDi, 2004), but an important role in the transition between the dynamics of the front and that of the body seems to be played by the sand input, since the change in mobility arises when fine particles enter the channel (around $t=0: 0: 22$ in Piantini et al., 2021f). Although the grain size distribution is mainly imposed by the storage area, the pulse's body is also subject to in-channel grain sorting: fine sediments percolate to the subsurface, while bigger grains are pushed upward and roll over them. Despite having the same size, we observe that the velocity of these elements is almost doubled compared to the particles constituting the front, and we advance the idea that size segregation is the driving mechanism for this enhanced mobility. It is worth noting that as a result of this process, a portion of the coarse upper layer of the body can eventually move ahead and reach the already developed front before it reaches the outlet section. That is why the first samples exceeding a value of $200 \mathrm{~g} \mathrm{~s}^{-1}$ of each sediment pulse, despite being considered part of the pulse's body because of the high solid discharge, are characterized by a consistent portion of coarse grains. As the solid concentration decreases, the tail of the sediment pulse is no longer congested and is characterized by saltation dynamics $(t=0: 0: 35$ in Piantini et al., 2021f). As opposed to the front, which has comparable solid discharge values, the tail of the pulse is also composed of fine grains. As a consequence, thanks to enhanced transport capacity (Wilcock et al., 2001; Curran and Wilcock, 2005), the coarsest fraction of the mixture moves relatively fast. These varying dynamics are missing for the second solid discharge peak, which exhibits constant bedload dynamics (Piantini et al., 2021g). 
(a) Flow surface elevation

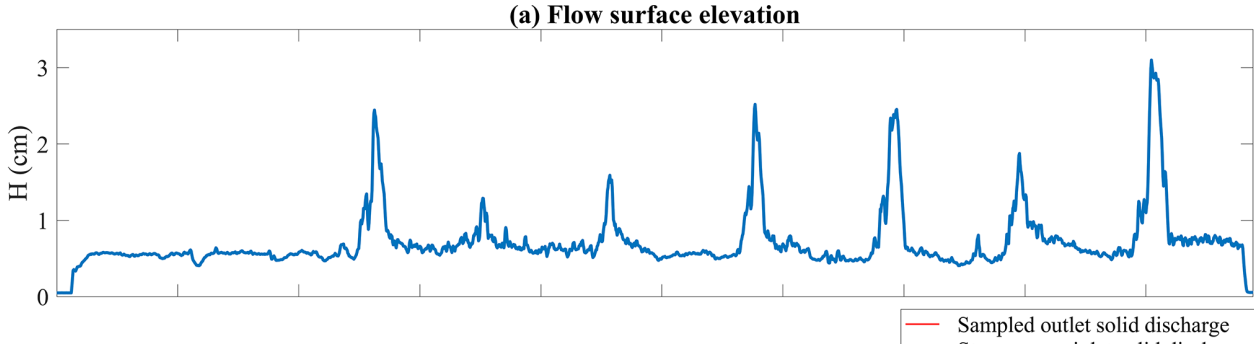

(b) Solid discharge

Storage area inlet solid discharge

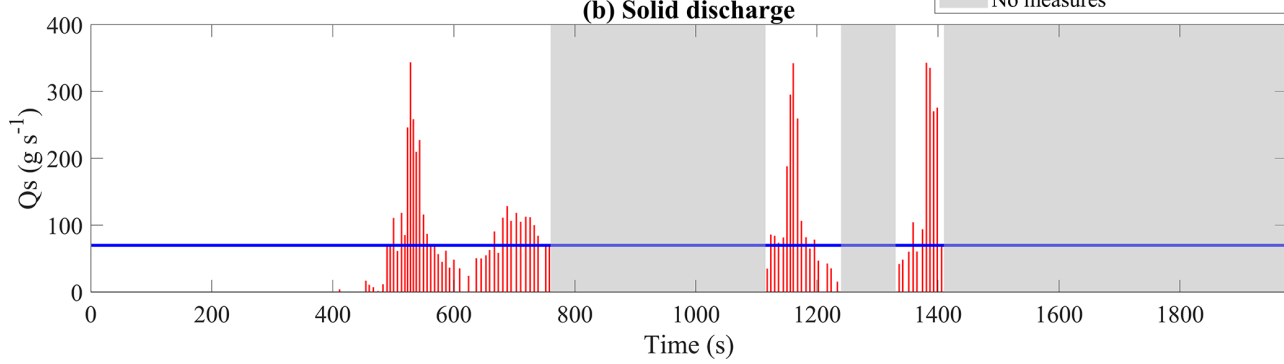

Figure 6. In-channel measurement time series of flow surface elevation and solid discharge. Panel (a) shows flow surface elevation as measured in the middle section. Panel (b) shows outlet solid discharge (red bars) compared with inlet solid discharge (blue horizontal line). It is worth recalling that these measurements refer to a different experiment from that presented in Sect. 3.1.

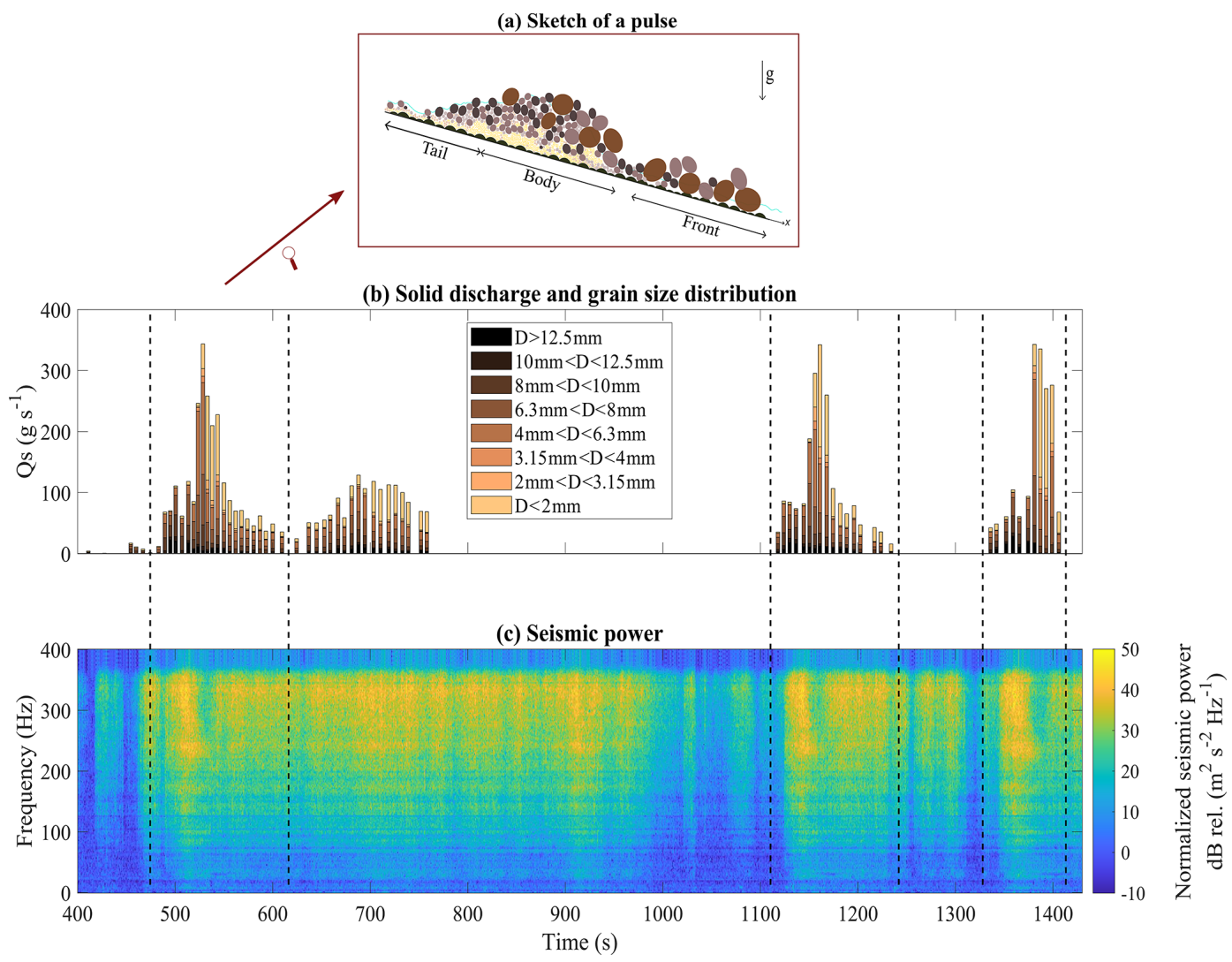

Figure 7. (a) Sketch of the sediment pulse. Sediment pulses can be divided into three parts: a front, a body, and a tail. (b) The four sampled pulses and the small solid discharge peak are presented with their grain size distribution. Each coloured bar refers to the particle diameter displayed in the legend, while the bar length is proportional to the percentage in weight of the related particle size. (c) Seismic power detected in the middle section of the flume. The seismic power is normalized with the mean seismic power computed under no sediment transport conditions, and it is shown as a function of time and frequency; different colours refer to different levels of power. 


\subsection{Pulse-induced seismic motion}

The passage of sediment pulses is associated with significant increases in seismic power over the whole frequency range, with the highest variations occurring above $200 \mathrm{~Hz}$ and being of about $30 \mathrm{~dB}$ (Fig. 7c; e.g. $t=500 \mathrm{~s}$ to $t=1000 \mathrm{~s}$ and $t=1100 \mathrm{~s}$ to $t=1450 \mathrm{~s}$ ). Comparing the outlet solid discharge samples and the spectrogram (Fig. 7) we observe that seismic power varies considerably during the sediment pulse. The highest mean power always corresponds to the passage of the front, while the body and the tail are comparatively associated with much lower values $(-9$ and $-6 \mathrm{~dB}$, respectively, compared to the front). We verify the fact that the highest seismic power is indeed exclusively due to the passage of the pulse's front thanks to video recordings, in which we observe that (i) most of the channel is occupied by the front, and the sediment pulse body is not yet present when the peak of seismic power is reached; and (ii) seismic power starts decreasing when the front's particles get out of the channel. Similarly, the seismic signature of the second peak solid discharge is characterized by a high level of seismic power above $200 \mathrm{~Hz}$, but as opposed to that of bigger sediment pulses, seismic power is proportional to solid discharge, with higher seismic power in the $200-300 \mathrm{~Hz}$ frequency range during the passage of higher solid discharge.

\section{Discussion}

\subsection{The impact of the experimental conditions on the behaviour of the upstream storage area}

Here we discuss the extent to which the geometric specificities of the storage area (e.g. the size and slope of the basin) as well as the boundary conditions (i.e. the input discharges) may have an impact on our observations. The size of the storage area controls the maximum volume of the deposit. A bigger size takes longer to fully fill before the deposit approaches the downstream channel and destabilizes; therefore, longer periods of aggradation are expected. In such a case, the magnitude of the erosion phase (i.e. the eroded volume) might be bigger given the larger surface exposed to the flow. By contrast, a smaller storage area might mean more frequent but smaller destabilizations. Similar implications are expected through varying the basal slope of the storage area, since a higher slope would exert stronger stresses on particles due to gravity, likely leading to more frequent and smaller destabilizations and vice versa. Different inputs of liquid and solid discharges may also have an impact on the frequency and magnitude of destabilization cycles: the former by changing the stress on the surface particles and the latter by affecting the rate of aggradation. Thus, we believe that the frequency and magnitude of aggradation and erosion phases are mainly set by the geometry of the storage area and the boundary conditions. As a result, we avoid interpreting these aspects and concentrate our analysis on the processes associated with destabilization.

\subsection{The control of the finest fraction on the en masse destabilization of sediment accumulation zones}

This experimental setup has been designed to investigate if a self-formed deposit could generate sediment pulses for a downstream channel. We find that the bimodal deposit (main experiment) exhibits a pulsating behaviour, i.e. self-induced alternating phases of storage and release of sediments under steady external forcing. In our experiments, the period of each cycle is likely dependent on the deposit's surface slope variations, since the major destabilizations of the deposit always occur within a small range of longitudinal gradient $(48 \% \pm 3 \%)$ and the following aggradation phases as well $(23 \% \pm 1 \%)$. However, we suggest that the dynamics of these alternating phases are mainly controlled by the presence of a fine fraction (sand in our experiments) and its downward percolation.

While kinematic sieving stabilizes the deposit during the aggradation phase by building a coarse armour on the surface as observed in alluvial beds (Recking et al., 2009; Bacchi et al., 2014), the presence of sand in the subsurface not only triggers but also enhances en masse erosion. We link the triggering mechanism to a decrease in the deposit's hydraulic conductivity: when sand moves downward in the mixture, it fills the interstices between grains and obstructs the subsurface water flow; as water can hardly infiltrate, a surface flow develops and starts increasing shear stresses on the particles constituting the armour, which is consequently prone to instability when a certain slope is reached. The effect of fines on the hydraulic conductivity of a sediment deposit and its failure has been investigated by $\mathrm{Hu}$ et al. $(2017,2018)$ with flume experiments on the initiation of flow-like landslides. The authors show that the low hydraulic conductivity of mixtures rich in fines (called "small particles" in the above-mentioned papers to underline their non-cohesive nature) promotes pore pressure build-up and the consequent failure of the granular deposit. Similarly, fines' availability has been proposed as a factor able to lower the threshold of debris flow initiation from loose sediment deposit for increasing pore water pressure (Baer et al., 2017). Since our experimental equipment does not allow us to estimate pore pressure, we cannot draw conclusions about its potential increase upon failure. However, the video recording makes us hypothesize that surface water flow exerts a major control on the destabilization process. We do not observe a well-defined slope rupture of the soil but rather the disintegration of the deposit's armour that slides downstream under drag forces (e.g. $t=0: 05: 32$ or $t=0: 08: 25$ in Piantini et al., 2021a). It is only at a later stage that the incision deepens due to the formation of a channelized flow (e.g. $t=0: 06: 45$ ).

Thus, we propose that large parts of a deposit's armour fail en masse once the deposit is destabilized thanks to 
the percolated sand, which acts as a carpet over which the overlying grains slide. This "granular lubrication" effect has been reported in previous works, wherein small particles are shown to increase the run-out length of granular avalanches (Linares-Guerrero et al., 2007; Phillips et al., 2006) and the mobility of the granular column (Lai et al., 2017). Interestingly, $\mathrm{Hu}$ et al. (2017) wonder if the viscous interface between water and small particles could affect the flow sliding: our observations of granular lubrication can be seen as additional evidence supporting their intuition. Changes in pore pressures occurring after soil failure have also been shown to help debris flow mobilization by decreasing its frictional strength until liquefaction (Iverson, 1997; Iverson et al., 1997). Although this process could help destabilization in our experiments, we believe that its effect is not major since the armoured surface is made of coarse grains, ensuring relatively efficient drainage conditions and thus likely preventing large pore pressure build-ups. Iverson et al. (1997) point out that the transition from localized failure to wider and generalized sediment flow might also occur without contraction (i.e. without additional pore pressure variations) if the mass becomes agitated enough by developing granular temperature while moving downslope, which may also occur in our case.

The experiments using the uniform coarse material and the bimodal mixture characterized by a low fraction of sand (Run R2 and Run R3, respectively) support our hypotheses since for equal boundary conditions the deposit shows highly inhibited mobility without any releases to the channel. Run R2 is characterized by a high hydraulic conductivity, and the deposit behaves like a dry granular pile with small grain avalanches that barely spread over the storage area. Run R3 is characterized by the development of a limited surface water flow and a single destabilization with an extremely confined run-out ( $t=0: 03: 45$ in Piantini et al., 2021d), with no channelized flows eroding the mass.

Although the processes that drive the massive failure of sediment accumulation zones may be many, the presence of a fine fraction seems to be the common denominator. Therefore, we propose that the granulometric composition of deposits should be carefully taken into account to assess their propensity to abruptly evacuate material to downstream channels. We acknowledge that direct field measurements are often difficult to carry out in the upper part of mountain catchments, but geological maps and high-resolution topographic surveys (Loye et al., 2016) could be sufficient for a diagnostic analysis of grain size distribution, as the amount of the small-sized fraction mostly depends on the local lithology and type of mass-wasting process involved in sediment production (e.g. fragmentation in rock avalanches as in Zhang and McSaveney, 2017, and landslides as in Davies and McSaveney, 2009).

\subsection{The dynamics of sediment pulse body as set by the} sand input from the storage area

Our experiments show that the sediment pulses travel downstream with ephemeral interaction with the bed, since the channel is completely free of sediments after the passage of the pulse's tail. Here we would like to stress how the massive input of fine particles during the upstream erosion phase influences the dynamics of the pulse. While at the beginning the sediment pulse's front is characterized by intermittent dynamics and reduced velocity, the motion of the biggest particles is dramatically enhanced with the body's arrival and passage. Over one century ago Gilbert (1914) demonstrated that the introduction of fine particles could enhance the transport efficiency of a mixture, and many works investigated this process experimentally (Wilcock et al., 2001; Curran and Wilcock, 2005), but only recent experimental studies underline the role played by grain sorting (Recking et al., 2009; Bacchi et al., 2014; Dudill et al., 2018; Chassagne et al., 2020). Whereas Bacchi et al. (2014) and Dudill et al. (2018) show that fines enhance the mobility of big particles by smoothing the surface where they move, Chassagne et al. (2020) propose from numerical modelling that after percolation fines can create a "conveyor belt" transporting the overlying coarse grains at higher velocity. Although the authors showed that an exclusive conveyor belt contribution to the increased mobility of larger grains implies a net separation between the two main sizes, which is missing in our experiments since particles are quite mixed on the surface, from the video recording big particles appear to be passively transported downstream over a fast layer of small grains (blue pebbles over a yellowish carpet from $t=0: 0: 25$ to $t=0: 0: 32$ in Piantini et al., 2021f). These observations lead us to suggest that the efficiency with which the pulse's body is digested by the channel without leaving any trace mainly depends on the capability of fine particles to carry coarser particles as a result of grain sorting, rather than hydrodynamics.

\subsection{Similarities with debris flow events}

Sediment pulse dynamics exhibit characteristics remarkably similar to those of stony debris flows (Takahashi, 2014). A first similarity consists of the granulometric composition: a front made of boulders, a body characterized by a wide grain size distribution, and a much more diluted tail (Iverson, 1997; Stock and Dietrich, 2006; Takahashi, 2014). To our knowledge this feature has been exclusively associated with processes occurring in the transportation zone such as in-channel size segregation (Iverson, 1997). Although we observe this latter process as well, our experimental work shows that a selective entrainment of grains also occurs in initiation zones, which can then have a significant role in influencing the textural composition of downstream-propagating pulses. Given the difficulty of carrying out direct field observations in ini- 
tiation zones (Berti et al., 1999; Imaizumi et al., 2006; McCoy et al., 2012; Loye et al., 2016), we suggest that this kind of experimental setup could be useful for investigating the mechanisms of both debris flow initiation and transportation.

Our findings also confirm the hypothesis of Kean (2013) for which the presence of a sediment accumulation zone can play a key role in the triggering of cyclic debris flow surges resulting from alternate aggradation and mass failure phases. In particular, the authors point out that the regressive instabilities (sensu Zanuttigh and Lamberti, 2007) of debris flows that are generated by water runoff (i.e. runoff-induced debris flows) may develop thanks to the presence of local lowslope sections of the channel where sediments can temporally be stored and then suddenly released. Channel portions characterized by a local decrease in sediment transport capacity, referred to as "sediment capacitors", can turn steady or quasi-steady supply conditions into discrete debris flow pulses. In modelling this phenomenon, Kean et al. (2013) use a uniform grain size distribution but acknowledge that a wide grain size distribution might affect surge characteristics. Our experiments corroborate this consideration and further stress how the granulometric composition of deposits can exacerbate the pulsating behaviour of debris flows.

\subsection{Links between pulse dynamics and seismic noise}

We observe a complex seismic response to sediment pulses characterized by a non-unique dependency of seismic power on sediment transport characteristics such as grain size and sediment flux. The highest seismic power is caused by the propagating front, consistent with the presence of larger grains causing more energetic impacts (Tsai et al., 2012). However, reduced seismic power is observed during the passage of the pulse body, although this latter is associated with the highest sediment flux, a parameter which is often aimed at being inverted from the seismic signal (Tsai et al., 2012; Bakker et al., 2020). Using the prediction of Tsai et al. (2012) that seismic power approximately scales as $D_{94}^{3} q_{\mathrm{s}}$, where $D$ is the particle diameter and $q_{\mathrm{s}}$ is sediment flux, we find that the reduced seismic power of $9 \mathrm{~dB}$ between the front and the body of the pulse cannot be explained solely by changes in $D$ and $q_{\mathrm{s}}$, since $D$ decreasing by about a factor of 0.7 ( $D_{94}=12.93 \mathrm{~mm}$ for the front compared to $D_{94}=9.32 \mathrm{~mm}$ for the body) and $q_{\mathrm{s}}$ increasing by about a factor of 4 (from $80 \mathrm{~g} \mathrm{~s}^{-1}$ for the front up to $340 \mathrm{~g} \mathrm{~s}^{-1}$ for the body) would yield approximately constant seismic power. Since seismic records show reduced sensitivity to the pulse's body, which in fact accounts for the largest fraction of the sediment flux, the capability of existing models to reliably invert solid discharge from seismic power is questioned for this kind of transport process.

Since our sediment pulses show similarities with debris flows (see Sect. 4.4), we find it appropriate to also compare our observations with expectations from theories of debrisflow-induced seismic noise. Conveniently, the limited chan- nel length in our experimental setup allows us to study the seismic responses of the three different parts of the pulse (front, body, and tail) separately, since when one component of the pulse acts the other one is not yet on the channel or has already left it. In contrast, in the field all parts of the pulse can potentially contribute to the overall measured seismic noise such that the drop in seismic power observed in our experiments during the passage of the body could be "hidden" in the field by the seismic noise induced by a louder upstream tail and downstream front. Our observations are consistent with most field surveys and models, for which the front (sometimes referred to as the snout) generates stronger seismic power than the following flow as it carries the largest clasts (Arattano and Moia, 1999; Lai et al., 2018; Coviello et al., 2019; Farin et al., 2019; Allstadt et al., 2020). However, the relationship between seismic noise and flow thickness is contrasting. While some observations show correlation between flow thickness and fluctuating basal stresses (Allstadt et al., 2020) and some models reveal no or rare direct dependence (Lai et al., 2018; Farin et al., 2019), our experiments show a clear negative correlation since a pulse's body is characterized by the peak of flow surface elevation (Fig. 6). According to Cole et al. (2009) and Allstadt et al. (2020), this could be explained by the body's high bulk density. Indeed, they observe a negative correlation between bulk density and seismic noise and therefore propose that more agitated flows are "louder" than denser and plug-like flows. This interpretation would also be consistent with the increase in seismic noise associated with the pulse's tail, which is again much more diluted than the body.

Further work remains to be conducted in order to fully unravel the control of the pulse's internal dynamics on the generated seismic noise. In particular, it appears essential to more quantitatively investigate the effect of grain sorting, which likely plays a crucial role by pushing the biggest particles upward, thus preventing them from directly impacting the bed and reducing their contribution to seismic noise. This would be consistent with the field observations of Kean et al. (2015), who suggest that the presence of a sediment layer over the bedrock can strongly damp the seismic signal generated by a debris flow. Detailed analysis of particle impact velocities, rates, and applied forces across the different grain sizes and the different pulse components would help further address these aspects.

\section{Conclusions}

We carry out flume experiments characterized by an original setup wherein instead of feeding the flume section directly as usually done, we supply liquid and solid discharge to a low-slope storage zone acting like a natural sediment accumulation zone and connected to a $18 \%$ steep channel.

Under constant feeding conditions, when a bimodal grain size distribution with a high fraction of fine particles is used, 
the storage area is subject to alternating aggradation and erosion phases. The high morphological mobility of the deposit is due to several autogenic processes, but the presence of sand appears to play a key role. In particular, if during the aggradation phase grain sorting enhances the stability of the deposit in coarsening its surface thanks to the downward percolation of the fine particles, we propose that the infilling of the subsurface with fine material contributes to the destabilization of the deposit by two means: (i) it reduces the hydraulic conductivity of the deposit and causes the formation of a significant surface water flow that in turn increases the stresses over the armoured layer, and (ii) it acts like a smooth carpet on which the coarser grains slide en masse.

The erosion phases correspond to the generation of sediment pulses towards the downstream channel. The evolution of the sediment deposit affects not only the magnitude of the sediment pulses, but also their rheology and dynamics. When major destabilizations of the sediment deposit occur, each sediment pulse can be divided into three different components as follows: a front having a low solid discharge made of the coarsest fraction of the sediment mixture inherited by the destabilization of deposit's surface; a body that corresponds to the peak of solid discharge composed of a high concentration of sand coming from the deposit's subsurface; and a tail characterized by low solid discharge and a wide grain size distribution, with sediments still transported while the next aggradation phase starts to develop in the storage area.

Pulses in sediment transport can be detected by seismic measurements. We find that the sediment pulse's front dominates the overall seismic noise. However, we report a complex link between seismic power and the different parts of the sediment pulse, which questions the validity of current models and theories for such transport dynamics. Further work is needed to unravel the role of the different pulses' geometrical and dynamical parameters in the generated seismic noise.

From a practical point of view, these results have strong implications for natural risk management. First, we show that the proximity of upstream sediment accumulation zones must be considered a potential source of sediment pulses for mountain rivers, regardless of bed sediment availability. Second, since the grain size distribution is shown to have a direct influence on the mobility (i.e. stability) of debris deposits, we challenge the classical approach for which the sediment budget of mountain catchments is merely reduced to an available volume and hydrological conditions are considered the main factor controlling the activation of external sediment supply. Instead, the granular conditions of deposits that are coupled with mountain streams or stored in the low-slope portion of the channel should be taken into account for assessing the occurrence and dynamics of such dramatic transport events. Finally, our seismic findings challenge the application of current theoretical frameworks to inverting bedload flux from the seismic noise associated with this kind of transport process.
Data availability. The data analysed during the current study are available on the Zenodo platform via https://doi.org/10.5281/zenodo.5552189 (Piantini et al., 2021h).

Video supplement. The Video Supplements of this study are available on the TIB AV-Portal via https://av.tib.eu/series/1044 (last access: 3 November 2021).

Video 1: Storage area with bidomal mixture, https://doi.org/10.5446/51666 (Piantini et al., 2021a).

Video 2: Storage area with fine mixture, https://doi.org/10.5446/51981 (Piantini et al., 2021b).

Video 3: Storage area with coarse mixture, https://doi.org/10.5446/51982 (Piantini et al., 2021c).

Video 4: Storage area with bidomal mixture (low fraction of sand), https://doi.org/10.5446/51984 (Piantini et al., 2021d).

Video 5: Sediment flux during the supplementary experiment, https://doi.org/10.5446/51985 (Piantini et al., 2021e).

Video 6: Sediment pulse during the main experiment, https://doi.org/10.5446/51986 (Piantini et al., 2021f).

Video 7: Solid discharge peak during the main experiment, https://doi.org/10.5446/51987 (Piantini et al., 2021g).

Supplement. The supplement related to this article is available online at: https://doi.org/10.5194/esurf-9-1423-2021-supplement.

Author contributions. MP, AR, and FG designed the laboratory experiments. MP developed the flume, and HB led the installation of the instrumental equipment. MP carried out the experiments with the help of HB. MP interpreted the results, with input from FG, AR, and HB. MP led the writing of the paper, and FG and AR revised and contributed to it.

Competing interests. The authors declare that they have no conflict of interest.

Disclaimer. Publisher's note: Copernicus Publications remains neutral with regard to jurisdictional claims in published maps and institutional affiliations.

Acknowledgements. We acknowledge the support of the INRAE Research Centre of Grenoble for the laboratory and instrumental equipment. We thank Christian Eymond-Gris, Frédéric Ousset, and Xavier Ravanat for the technical support in the development of the flume. We thank Maarten Bakker for helping in the analysis of the seismic data. We thank Guillaume Piton for the constructive discussion on the experimental scaling of the flume. We thank the two anonymous reviewers for comments which helped improve the quality of the paper.

Financial support. This research has been supported by the Agence Nationale de la Recherche (grant no. 17-CE01-0008). 
Review statement. This paper was edited by Francois Metivier and reviewed by two anonymous referees.

\section{References}

Allstadt, K. E., Farin, M., Iverson, R. M., Obryk, M. K., Kean, J. W., Tsai, V. C., Rapstine, T. D., and Logan, M.: Measuring Basal Force Fluctuations of Debris Flows Using Seismic Recordings and Empirical Green's Functions, J. Geophys. Res.-Earth Surf., 125, 9, https://doi.org/10.1029/2020JF005590, 2020.

Arattano, M. and Moia, F.: Monitoring the propagation of a debris flow along a torrent, Hydrolog. Sci. J., 44, 811-823, https://doi.org/10.1080/02626669909492275, 1999.

Arran, M. I., Mangeney, A., De Rosny, J., Farin, M., Toussaint, R., and Roche, O.: Laboratory Landquakes: Insights From Experiments Into the High-Frequency Seismic Signal Generated by Geophysical Granular Flows, J. Geophys. Res.-Earth Surf., 126, 5, https://doi.org/10.1029/2021JF006172, 2021.

Asano, Y. and Uchida, T.: Detailed documentation of dynamic changes in flow depth and surface velocity during a large flood in a steep mountain stream, J. Hydrol., 541, 127-135, https://doi.org/10.1016/j.jhydrol.2016.04.033, 2016.

Bacchi, V., Recking, A., Eckert, N., Frey, P., Piton, G., and Naaim, M.: The effects of kinetic sorting on sediment mobility on steep slopes, Earth Surf. Process. Landforms, 39, 1075-1086, https://doi.org/10.1002/esp.3564, 2014.

Badoux, A., Andres, N., and Turowski, J. M.: Damage costs due to bedload transport processes in Switzerland, Nat. Hazards Earth Syst. Sci., 14, 279-294, https://doi.org/10.5194/nhess-14-2792014, 2014.

Baer, P., Huggel, C., McArdell, B. W., and Frank, F.: Changing debris flow activity after sudden sediment input: a case study from the Swiss Alps, Geology Today, 33, 216-223, https://doi.org/10.1111/gto.12211, 2017.

Bakker, M., Gimbert, F., Geay, T., Misset, C., Zanker, S., and Recking, A.: Field Application and Validation of a Seismic Bedload Transport Model, J. Geophys. Res.-Earth Surf., 125, 5, https://doi.org/10.1029/2019JF005416, 2020.

Bathurst, J. C., Graf, W. H., and Cao, H. H.: Initiation of sediment transport in steep channels with coarse bed material, in: Mechanics of Sediment Transport, edited by: Sumer, B. M. and Müller, A., CRC Press, 207-213, https://doi.org/10.1201/9781003079019-27, 1983.

Benda, L. and Dunne, T.: Stochastic forcing of sediment routing and storage in channel networks, Water Resour. Res., 33, 2865-2880, https://doi.org/10.1029/97WR02387, 1997.

Berti, M., Genevois, R., Simoni, A., and Tecca, P. R.: Field observations of a debris flow event in the Dolomites, Geomorphology, 29, 265-274, https://doi.org/10.1016/S0169-555X(99)00018-5, 1999.

Bovis, M. J. and Jakob, M.: The role of debris supply conditions in predicting debris flow activity, 16, 1039-1054, https://doi.org/10.1002/(sici)10969837(199910)24:11<1039::aid-esp29>3.0.co;2-u, 1999.

Brummer, C. J. and Montgomery, D. R.: Influence of coarse lag formation on the mechanics of sediment pulse dispersion in a mountain stream, Squire Creek, North Cascades, Washington, United States, Water Resour. Res., 42, 7, https://doi.org/10.1029/2005WR004776, 2006.
Burtin, A., Hovius, N., and Turowski, J. M.: Seismic monitoring of torrential and fluvial processes, Earth Surf. Dynam., 4, 285-307, https://doi.org/10.5194/esurf-4-285-2016, 2016.

Casagli, N., Ermini, L., and Rosati, G.: Determining grain size distribution of the material composing landslide dams in the Northern Apennines: sampling and processing methods, Eng. Geol., 69, 83-97, https://doi.org/10.1016/S00137952(02)00249-1, 2003.

Chassagne, R., Maurin, R., Chauchat, J., and Frey, P.: Mobility of bidisperse mixtures during bedload transport, Phys. Rev. Fluids, 5, 114307, https://doi.org/10.1103/PhysRevFluids.5.114307, 2020.

Cole, S. E., Cronin, S. J., Sherburn, S., and Manville, V.: Seismic signals of snow-slurry lahars in motion: 25 September 2007, Mt Ruapehu, New Zealand, Geophys. Res. Lett., 36, L09405, https://doi.org/10.1029/2009GL038030, 2009.

Comiti, F., Cadol, D., and Wohl, E.: Flow regimes, bed morphology, and flow resistance in self-formed step-pool channels, Water Resour. Res., 45, 4, https://doi.org/10.1029/2008WR007259, 2009.

Cook, K. L., Andermann, C., Gimbert, F., Adhikari, B. R., and Hovius, N.: Glacial lake outburst floods as drivers of fluvial erosion in the Himalaya, Science, 362, 53-57, https://doi.org/10.1126/science.aat4981, 2018.

Coviello, V., Arattano, M., Comiti, F., Macconi, P., and Marchi, L.: Seismic Characterization of Debris Flows: Insights into Energy Radiation and Implications for Warning, J. Geophys. Res.-Earth Surf., 124, 1440-1463, https://doi.org/10.1029/2018JF004683, 2019.

Cui, Y. and Parker, G.: Numerical Model of Sediment Pulses and Sediment-Supply Disturbances in Mountain Rivers, J. Hydraul. Eng., 131, 646-656, https://doi.org/10.1061/(ASCE)07339429(2005)131:8(646), 2005.

Cui, Y., Parker, G., Lisle, T. E., Gott, J., Hansler-Ball, M. E., Pizzuto, J. E., Allmendinger, N. E., and Reed, J. M.: Sediment pulses in mountain rivers: 1. Experiments, Water Resour. Res., 39, 9, https://doi.org/10.1029/2002WR001803, 2003.

Curran, J. C. and Wilcock, P. R.: Effect of Sand Supply on Transport Rates in a Gravel-Bed Channel, J. Hydraul. Eng., 131, 961-967, https://doi.org/10.1061/(ASCE)07339429(2005)131:11(961), 2005.

Davies, T. R. and McSaveney, M. J.: The role of rock fragmentation in the motion of large landslides, Engineering Geology, 109, 6779, https://doi.org/10.1016/j.enggeo.2008.11.004, 2009.

Dudill, A., Lafaye de Micheaux, H., Frey, P., and Church, M.: Introducing Finer Grains Into Bedload: The Transition to a New Equilibrium, J. Geophys. Res.-Earth Surf., 123, 2602-2619, https://doi.org/10.1029/2018JF004847, 2018.

Farin, M., Tsai, V. C., Lamb, M. P., and Allstadt, K. E.: A physical model of the high-frequency seismic signal generated by debris flows, Earth Surf. Process. Landforms, 44, 2529-2543, https://doi.org/10.1002/esp.4677, 2019.

Fontana, G. D. and Marchi, L.: Slope-area relationships and sediment dynamics in two alpine streams, Hydrol. Process., 17, 7387, https://doi.org/10.1002/hyp.1115, 2003.

Frey, P. and Church, M.: How River Beds Move, Science, 325, 1509-1510, https://doi.org/10.1126/science.1178516, 2009.

GDR MiDi: On dense granular flows, Eur. Phys. J. E., 14, 341-365, https://doi.org/10.1140/epje/i2003-10153-0, 2004. 
Gilbert, G. K.: The transportation of debris by running water, US Geologial Survey, Washington, DC, 1914.

Gimbert, F., Tsai, V. C., and Lamb, M. P.: A physical model for seismic noise generation by turbulent flow in rivers, J. Geophys. Res.-Earth Surf., 119, 2209-2238, https://doi.org/10.1002/2014JF003201, 2014.

Gimbert, F., Fuller, B. M., Lamb, M. P., Tsai, V. C., and Johnson, J. P. L.: Particle transport mechanics and induced seismic noise in steep flume experiments with accelerometer-embedded tracers: Experimental Testing of Seismic Noise Generated by Sediment Transport, Earth Surf. Process. Landforms, 44, 219-241, https://doi.org/10.1002/esp.4495, 2019.

Govi, M., Maraga, F., and Moia, F.: Seismic detectors for continuous bed load monitoring in a gravel stream, Hydrological Sciences Journal, 38, 123-132, https://doi.org/10.1080/02626669309492650, 1993.

Gregoretti, C. and Fontana, G. D.: The triggering of debris flow due to channel-bed failure in some alpine headwater basins of the Dolomites: analyses of critical runoff, Hydrol. Process., 22, 2248-2263, https://doi.org/10.1002/hyp.6821, 2008.

Hu, W., Scaringi, G., Xu, Q., Pei, Z., Van Asch, T. W. J., and Hicher, P.-Y.: Sensitivity of the initiation and runout of flowslides in loose granular deposits to the content of small particles: An insight from flume tests, Engineering Geology, 231, 34-44, https://doi.org/10.1016/j.enggeo.2017.10.001, 2017.

$\mathrm{Hu}$, W., Scaringi, G., Xu, Q., and Huang, R.: Internal Erosion Controls Failure and Runout of Loose Granular Deposits: Evidence From Flume Tests and Implications for Postseismic Slope Healing, Geophys. Res. Lett., 45, 5518-5527, https://doi.org/10.1029/2018GL078030, 2018.

Imaizumi, F., Sidle, R. C., Tsuchiya, S., and Ohsaka, O.: Hydrogeomorphic processes in a steep debris flow initiation zone: Hydrogeomorphology of debris flow sites, Geophys. Res. Lett., 33, 10, https://doi.org/10.1029/2006GL026250, 2006.

Iverson, R. M.: The physics of debris flows, Rev. Geophys., 35, 245-296, https://doi.org/10.1029/97RG00426, 1997.

Iverson, R. M., Reid, M. E., and LaHusen, R. G.: Debris-flow mobilization from landslides, Annu. Rev. Earth Planet. Sci., 25, 85138, https://doi.org/10.1146/annurev.earth.25.1.85, 1997.

Kean, J. W., McCoy, S. W., Tucker, G. E., Staley, D. M., and Coe, J. A.: Runoff generated debris flows: Observations and modeling of surge initiation, magnitude, and frequency, J. Geophys. Res.Earth, 118, 2190-2207, 2013.

Kean, J. W., Coe, J. A., Coviello, V., Smith, J. B., McCoy, S. W., and Arattano, M.: Estimating rates of debris flow entrainment from ground vibrations, Geophys. Res. Lett., 42, 6365-6372, https://doi.org/10.1002/2015GL064811, 2015.

Lai, V. H., Tsai, V. C., Lamb, M. P., Ulizio, T. P., and Beer, A. R.: The Seismic Signature of Debris Flows: Flow Mechanics and Early Warning at Montecito, California, Geophys. Res. Lett., 45, 5528-5535, https://doi.org/10.1029/2018GL077683, 2018.

Lai, Z., Vallejo, L. E., Zhou, W., Ma, G., Espitia, J. M., Caicedo, B., and Chang, X.: Collapse of Granular Columns With Fractal Particle Size Distribution: Implications for Understanding the Role of Small Particles in Granular Flows, Geophys. Res. Lett., 44, 24, https://doi.org/10.1002/2017GL075689, 2017.

Lamand, E., Piton, G., and Recking, A.: Hydrologie et hydraulique torrentielle, étude d'un cas pratique: la Roize, hal-02605416, 89 pp., 2017.
Lamb, M. P., Dietrich, W. E., and Venditti, J. G.: Is the critical Shields stress for incipient sediment motion dependent on channel-bed slope?, J. Geophys. Res., 113, F02008, https://doi.org/10.1029/2007JF000831, 2008.

Lee, A. J. and Ferguson, R. I.: Velocity and flow resistance in step-pool streams, Geomorphology, 46, 59-71, https://doi.org/10.1016/S0169-555X(02)00054-5, 2002.

Lenzi, M. A., Mao, L., and Comiti, F.: Magnitude-frequency analysis of bed load data in an Alpine boulder bed stream, Water Resour. Res., 40, 7, https://doi.org/10.1029/2003WR002961, 2004.

Linares-Guerrero, E., Goujon, C., and Zenit, R.: Increased mobility of bidisperse granular avalanches, J. Fluid Mech., 593, 475-504, https://doi.org/10.1017/S0022112007008932, 2007.

Lisle, T. E., Pizzuto, J. E., Ikeda, H., Iseya, F., and Kodama, Y.: Evolution of a sediment wave in an experimental channel, Water Resour. Res., 33, 1971-1981, https://doi.org/10.1029/97WR01180, 1997.

Loye, A., Jaboyedoff, M., Theule, J. I., and Liébault, F.: Headwater sediment dynamics in a debris flow catchment constrained by high-resolution topographic surveys, Earth Surf. Dynam., 4, 489-513, https://doi.org/10.5194/esurf-4-489-2016, 2016.

Mao, L. and Lenzi, M. A.: Sediment mobility and bedload transport conditions in an alpine stream, Hydrol. Process., 21, 1882-1891, https://doi.org/10.1002/hyp.6372, 2007.

Mao, L., Cavalli, M., Comiti, F., Marchi, L., Lenzi, M. A., and Arattano, M.: Sediment transfer processes in two Alpine catchments of contrasting morphological settings, J. Hydrol., 364, 88-98, https://doi.org/10.1016/j.jhydrol.2008.10.021, 2009.

McCoy, S. W., Kean, J. W., Coe, J. A., Tucker, G. E., Staley, D. M., and Wasklewicz, T. A.: Sediment entrainment by debris flows: In situ measurements from the headwaters of a steep catchment, J. Geophys. Res., 117, F03016, https://doi.org/10.1029/2011JF002278, 2012.

Parker, G., Paola, C., Whipple, K. X., and Mohrig, D.: Alluvial Fans Formed by Channelized Fluvial and Sheet Flow. I: Theory, J. Hydraul. Eng., 124, 985-995, https://doi.org/10.1061/(ASCE)07339429(1998)124:10(985), 1998.

Peakall, J., Ashworth, P., and Best, J.: Physical modelling in fluvial geomorphology: principles, applications and unresolved issues, in: The scientific nature of geomorphology: proceedings of the 27th Binghamton Symposium in Geomorphology, John Wiley and Sons, Chichester, 221-253, ISBN 047196811 0, 1996.

Phillips, J., Hogg, A., Kerswell, R., and Thomas, N.: Enhanced mobility of granular mixtures of fine and coarse particles, Earth Planet. Sc. Lett., 246, 466-480, https://doi.org/10.1016/j.epsl.2006.04.007, 2006.

Piantini, M., Gimbert, F., Bellot, H., and Recking, A.: Video 1: Storage area with bidomal mixture, https://doi.org/10.5446/51666, 2021a.

Piantini, M., Gimbert, F., Bellot, H., and Recking, A.: Video 2: Storage area with fine mixture, https://doi.org/10.5446/51981, 2021b.

Piantini, M., Gimbert, F., Bellot, H., and Recking, A.: Video 3: Storage area with coarse mixture, https://doi.org/10.5446/51982, 2021c.

Piantini, M., Gimbert, F., Bellot, H., and Recking, A.: Video 4: Storage area with bidomal mixture (low fraction of sand), https://doi.org/10.5446/51984, 2021d. 
Piantini, M., Gimbert, F., Bellot, H., and Recking, A.: Video 5: Sediment flux during the supplementary experiment, https://doi.org/10.5446/51985, 2021e.

Piantini, M., Gimbert, F., Bellot, H., and Recking, A.: Video 6: Sediment pulse during the main experiment, https://doi.org/10.5446/51986, $2021 \mathrm{f}$.

Piantini, M., Gimbert, F., Bellot, H., and Recking, A.: Video 7: Solid discharge peak during the main experiment, https://doi.org/10.5446/51987, 2021g.

Piantini, M., Gimbert, F., Bellot, H., and Recking, A.: Triggering and propagation of exogeneous sediment pulses in mountain channels: insights from flume experiments with seismic monitoring, Zenodo [data set], https://doi.org/10.5281/zenodo.5552189, $2021 \mathrm{~h}$.

Piton, G.: Sediment transport control by check dams and open check dams in Alpine torrents, Doctoral dissertation, Univ. Grenoble Alpes, IRSTEA, Centre de Grenoble, 2016.

Piton, G. and Recking, A.: The concept of travelling bedload and its consequences for bedload computation in mountain streams, Earth Surf. Process. Landforms, 42, 1505-1519, https://doi.org/10.1002/esp.4105, 2017.

Prancevic, J. P. and Lamb, M. P.: Unraveling bed slope from relative roughness in initial sediment motion: Relative roughness and incipient motion, J. Geophys. Res.-Earth Surf., 120, 474489, https://doi.org/10.1002/2014JF003323, 2015.

Prancevic, J. P., Lamb, M. P., and Fuller, B. M.: Incipient sediment motion across the river to debris-flow transition, 42, 191-194, https://doi.org/10.1130/G34927.1, 2014.

Recking, A.: Theoretical development on the effects of changing flow hydraulics on incipient bed load motion, Water Resour. Res., 45, 4, https://doi.org/10.1029/2008WR006826, 2009.

Recking, A.: Influence of sediment supply on mountain streams bedload transport, Geomorphology, 175-176, 139-150, https://doi.org/10.1016/j.geomorph.2012.07.005, 2012.

Recking, A.: Relations between bed recharge and magnitude of mountain streams erosions, J. Hydro-environ. Res., 8, 143-152, https://doi.org/10.1016/j.jher.2013.08.005, 2014.

Recking, A., Frey, P., Paquier, A., Belleudy, P., and Champagne, J. Y.: Feedback between bed load transport and flow resistance in gravel and cobble bed rivers, Water Resour. Res., 44, 5, https://doi.org/10.1029/2007WR006219, 2008.

Recking, A., Frey, P., Paquier, A., and Belleudy, P.: An experimental investigation of mechanisms involved in bed load sheet production and migration, J. Geophys. Res., 114, F03010, https://doi.org/10.1029/2008JF000990, 2009.

Rickenmann, D. and Recking, A.: Evaluation of flow resistance in gravel-bed rivers through a large field data set, Water Resour. Res., 47, 7, https://doi.org/10.1029/2010WR009793, 2011.

Schneider, J. M., Turowski, J. M., Rickenmann, D., Hegglin, R., Arrigo, S., Mao, L., and Kirchner, J. W.: Scaling relationships between bed load volumes, transport distances, and stream power in steep mountain channels: Tracer Erlenbach, J. Geophys. Res.-Earth Surf., 119, 533-549, https://doi.org/10.1002/2013JF002874, 2014.

Schneider, J. M., Rickenmann, D., Turowski, J. M., Schmid, B., and Kirchner, J. W.: Bed load transport in a very steep mountain stream (Riedbach, Switzerland): Measurement and prediction, Water Resour. Res., 52, 9522-9541, https://doi.org/10.1002/2016WR019308, 2016.
Schumm, S. A.: The fluvial system, Repr., Blackburn Press, Caldwell, NJ, 338 pp., ISNB 193066579 2, 2003.

Sklar, L. S., Fadde, J., Venditti, J. G., Nelson, P., Wydzga, M. A., Cui, Y., and Dietrich, W. E.: Translation and dispersion of sediment pulses in flume experiments simulating gravel augmentation below dams, Water Resour. Res., 45, 8, https://doi.org/10.1029/2008WR007346, 2009.

Sklar, L. S., Riebe, C. S., Marshall, J. A., Genetti, J., Leclere, S., Lukens, C. L., and Merces, V.: The problem of predicting the size distribution of sediment supplied by hillslopes to rivers, Geomorphology, 277, 31-49, https://doi.org/10.1016/j.geomorph.2016.05.005, 2017.

Solari, L. and Parker, G.: The Curious Case of Mobility Reversal in Sediment Mixtures, J. Hydraul. Eng., 126, 185-197, https://doi.org/10.1061/(ASCE)0733-9429(2000)126:3(185), 2000.

Stock, J. D. and Dietrich, W. E.: Erosion of steepland valleys by debris flows, Geol. Soc. Am. Bull., 118, 1125-1148, https://doi.org/10.1130/B25902.1, 2006.

Sutherland, D. G., Ball, M. H., Hilton, S. J., and Lisle, T. E.: Evolution of a landslide-induced sediment wave in the Navarro River, California, 13, 1036-1048, https://doi.org/10.1130/00167606(2002)114<1036:EOALIS>2.0.CO;2, 2002.

Takahashi, T.: Debris flow: mechanics, prediction and countermeasures, CRC Press/Balkema, Boca Raton, Fla., 551 pp., ISBN 978 $1138073678,2014$.

Tsai, V. C., Minchew, B., Lamb, M. P., and Ampuero, J.P.: A physical model for seismic noise generation from sediment transport in rivers, Geophys. Res. Lett., 39, 2 , https://doi.org/10.1029/2011GL050255, 2012.

Turowski, J. M., Yager, E. M., Badoux, A., Rickenmann, D., and Molnar, P.: The impact of exceptional events on erosion, bedload transport and channel stability in a step-pool channel, Earth Surf. Process. Landforms, 34, 1661-1673, https://doi.org/10.1002/esp.1855, 2009.

Welch, P.: The use of fast Fourier transform for the estimation of power spectra: A method based on time averaging over short, modified periodograms, IEEE Trans. Audio Electroacoust., 15, 70-73, https://doi.org/10.1109/TAU.1967.1161901, 1967.

Wiberg, P. L. and Smith, J. D.: Velocity distribution and bed roughness in high-gradient streams, Water Resour. Res., 27, 825-838, https://doi.org/10.1029/90WR02770, 1991.

Wilcock, P. R., Kenworthy, S. T., and Crowe, J. C.: Experimental study of the transport of mixed sand and gravel, Water Resour. Res., 37, 3349-3358, https://doi.org/10.1029/2001WR000683, 2001.

Wohl, E. E.: Mountain rivers revisited, American Geophysical Union, Washington, DC, 573 pp., ISBN 978111867168 9, 2010.

Wolcott, J.: Nonfluvial Control of Bimodal GrainSize Distributions in River-Bed Gravels, SEPM JSR, 58, 6, https://doi.org/10.1306/212F8ED6-2B24-11D78648000102C1865D, 1988.

Zanuttigh, B. and Lamberti, A.: Instability and surge development in debris flows, Rev. Geophys., 45, 3, https://doi.org/10.1029/2005RG000175, 2007.

Zhang, M. and McSaveney, M. J.: Rock avalanche deposits store quantitative evidence on internal shear during runout: Avalanche Deposits Store Shear Evidence, Geophys. Res. Lett., 44, 8814 8821, https://doi.org/10.1002/2017GL073774, 2017. 
Zhang, Z., Walter, F., McArdell, B. W., Wenner, M., Chmiel, M., de Haas, T., and He, S.: Insights From the Particle Impact Model Into the High-Frequency Seismic Signature of Debris Flows, Geophys. Res. Lett., 48, 1, https://doi.org/10.1029/2020GL088994, 2021.
Zimmermann, A., Church, M., and Hassan, M. A.: Step-pool stability: Testing the jammed state hypothesis, J. Geophys. Res., 115, F02008, https://doi.org/10.1029/2009JF001365, 2010. 